\title{
Frischen Schwung bekommen
}

\author{
YOGA bei Gesundheitsproblemen — Junger Hund (puppy) heißt die übung, die wir \\ auf den Fotos sehen. Der Name passt: Ein junger Hund ist springlebendig und lebensfroh. \\ Und erfahrene Hunde haben gelernt, dass es öfter der Nachhilfe in Sachen Beweglichkeit \\ und Lebensfreude bedarf.
}

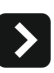

Wann ist die beste Zeit, um Yoga zu üben? Zwischendurch am Arbeitsplatz können Stand- und Sitzpositionen gut durchgeführt werden. Sie unterbrechen Routinen, senken den Stresslevel, verbessern das Körpergefühl und erhöhen die Aufmerksamkeit.

Wer gleich nach dem Aufwachen übt, dehnt Muskeln und Bänder, bewegt alle Gelenke, kurbelt den Kreislauf an, atmet durch und wird richtig wach.

Yoga in Gruppen während des Tages zu üben, ist ideal, um den Arbeitstag zu unterbrechen oder abzuschließen.

Für den Abend oder vor dem Schlafengehen eignen sich ruhige und entspannende Yoga-Übungen, die helfen abzuschalten und Ruhe zu finden. Egal, für welche Zeit Sie sich entscheiden, es ist günstig, Yoga-Übungszeiten regelmäßig wahrzunehmen, ohne sie immer wieder in Frage zu stellen. Denn: Eine regelmäßige Yoga-Praxis ist der Schlüssel zum Erfolg.

\section{Schnelle Wirkung}

Arme kreuzen: Stellen Sie sich aufrecht hin, strecken Sie beide Arme und über- kreuzen Sie diese vor Ihrem Körper. Die Handinnenflächen zeigen zu Ihrem Körper. Atmen Sie durch die Nase ein und heben Sie Ihre Arme seitlich hoch bis sie sich über dem Kopf wieder gestreckt überkreuzen. Jetzt zeigen die Handflächen nach vorn. Achten Sie darauf, dass Ihre Schultern entspannt bleiben, wenn Sie Ihre Arme über den Kopf strecken.

Atmen Sie durch die Nase aus und senken Sie dabei Ihre Arme bis sie wieder gestreckt vor Ihrem Körper überkreuzt sind. Wiederholen Sie diese Übung mindestens sechsmal.

\section{Anhaltende Wirkung}

Junger Hund: Die Ausgangsposition ist die Vierfüßlerposition. Sie wird im Yoga Tiger-Position genannt. Achten Sie darauf, dass Ihre Handgelenke unter Ihren Schultergelenken und Ihre Kniegelenke unter Ihren Hüftgelenken aufgestellt sind. Diese Positionierung schont Ihre Gelenke. Der Kopf bleibt in Verlängerung der Wirbelsäule, der Blick geht in Richtung Boden. In dieser Position die ganze Wirbelsäule bewusst lang strecken (Foto 1).
Ausatmend den Kopf nach links bewegen, ohne ihn dabei zu heben oder zu senken. Gleichzeitig die linke Schulter und die linke Seite der Hüfte aufeinander zu bewegen. Von oben betrachtet, formt der Körper ein „C“. Diese Position erinnert an einen Hund, der vor Freude mit seinem Hinterteil wedelt (Foto 2).

Einatmend wieder in die Ausgangsposition zurückgehen. Ausatmend die Übung zur anderen Seite wiederholen. Insgesamt die Übung mindestens zu jeder Seite sechsmal wiederholen.

Um die Position aufzulösen, bewegen Sie sich aus der Vierfüßlerposition heraus rückwärts, bis Ihr Gesäß auf den Fersen aufsitzt. Wenn Sie möchten, lassen Sie Ihre Hände fest am Boden und strecken noch einmal den Rücken in dieser Haltung. Dann die Hände neben den Knien rechts und links auf den Boden aufsetzen und mit einer Einatmung langsam Wirbel für Wirbel den Rücken aufrollen und in den Fersensitz kommen. Die Hände ruhen auf den Oberschenkeln. Zuletzt in dieser Position nachspüren. Die Augen schließen, wenn es angenehm ist.

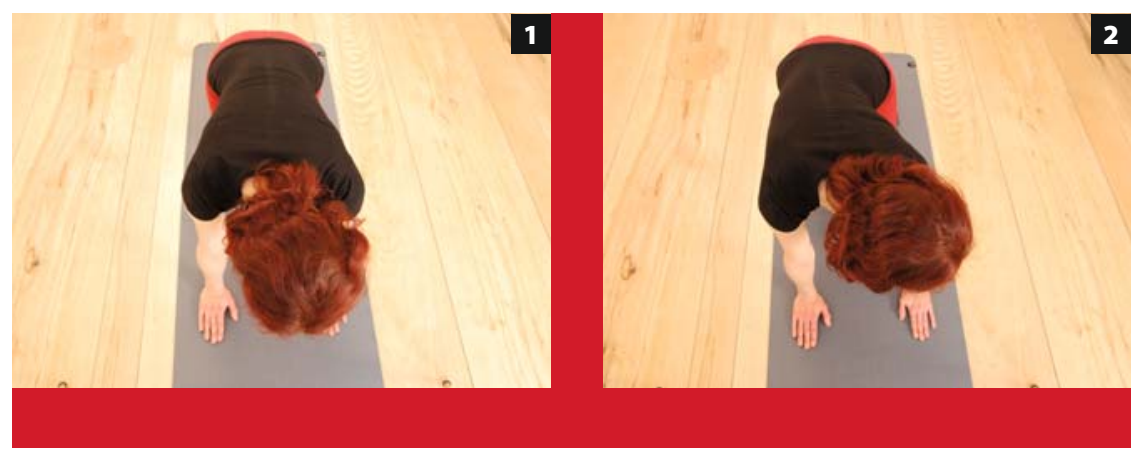

